DOI: http://dx.doi.org/10.22483/2177-5796.2017v19n2p291-306

\title{
Percepções de professores de Educação Física sobre educação inclusiva
}

\author{
Ramon Missias-Moreira
}

\begin{abstract}
Resumo: Este estudo objetivou analisar as percepções de professores de Educação Física sobre a inclusão de alunos com deficiência no sistema regular de ensino. Trata de uma pesquisa descritiva e analítica, qualitativa, tendo como informantes 9 professores de Educação Física de 3 escolas públicas estaduais do município de Jequié-Bahia. Foi utilizada como instrumento de coleta de dados a entrevista semiestruturada. Os dados foram analisados através da Técnica de Análise de Conteúdo Temática Categorial. Como resultados obtivemos 4 categorias: Percepção sobre educação inclusiva; A escola como espaço inclusivo; Formação profissional frente ao processo de inclusão e Prática pedagógica no contexto inclusivo. Concluímos que para ocorrer a inclusão no contexto regular faz-se necessária e urgente a formação continuada dos professores; aquisição de materiais e recursos para o trabalho; eliminação das barreiras arquitetônicas e, consequentemente, melhoria das condições de trabalho.
\end{abstract}

Palavras-chave: Percepção. Educação inclusiva. Inclusão.

\section{Perceptions of Physical Education teachers about inclusive education}

\begin{abstract}
This study aims to analyze the perception of physical education teachers about including students with special needs in regular education classes. This is a descriptive, analytics and qualitative study, and had as informants 9 Physical Education teachers of 3 public schools of Jequié, Bahia, Brazil. A semi-structured interview was used as an instrument for data collection. The data were analyzed through the theme/category-based content analysis technique. As results we obtained 4 categories: Perception on inclusive education; School as inclusive space; Professional formation about the inclusion process and Pedagogical practice in the inclusive context. We conclude that for occur the inclusion in regular context it is necessary and urgent the continued teacher training, acquisition of materials and resources for the work, elimination of architectural barriers and, consequently, improvement of working conditions.
\end{abstract}

Keywords: Perception. Inclusive education. Inclusion.

Quaestio, Sorocaba, SP, v. 19, n. 2, p. 291-306, ago. 2017. 


\section{Introdução}

A sociedade brasileira, sendo reconhecidamente marcada por uma história de poder de dominação, de preconceitos, de estigmas e de muitas outras práticas de caráter excludente, tratou a escola durante muito tempo e, muitos lugares e situações ainda hoje, com procedimentos que excluem os alunos com deficiência da rede regular de ensino, questionando seu acesso e sua permanência na classe regular, seja por discriminação, falta de qualificação e de estrutura adequada ou pela não aceitação das diferenças e do que foge do padrão da considerada normalidade.

Como está preconizado na Lei de Diretrizes e Bases da Educação Nacional nº 9.394/96, a educação básica tem por objetivo desenvolver no aluno o pleno exercício da cidadania, onde a inclusão social toma um papel essencial para a correção das injustiças sociais que marcaram a nossa história (BRASIL, 1996), além de receber atendimento educacional especializado para atender às suas necessidades de aprendizagem sempre que necessário.

A partir da implantação das Diretrizes Nacionais para a Educação Especial na Educação Básica (BRASIL, 2001) e da consolidação desses ideais através da Política Nacional de Educação Especial, na perspectiva da Educação Inclusiva (BRASIL, 2008), é preciso olhar o aluno com deficiência como outro qualquer, mas que precisa de atenção qualificada adequada e da estrutura escolar como um todo para aprender e desenvolver suas potencialidades.

Nesse sentido, Oliveira e Souza (2011) afirmam que apesar da LDB determinar que essa modalidade de educação deva ser oferecida na rede regular de ensino e assegurada pelos sistemas de ensino, na prática evidencia-se uma grande diferença entre o que é requerido no discurso normativo e o que vem ocorrendo na prática concreta. Não adianta apenas substituir as terminologias que se apresentam reforçadas de preconceitos e legitimam a discriminação de cidadãos que não se enquadram nos padrões de "normalidade" definidos por essa sociedade dominadora. Normalidade no sentido de questionamento do conceito racional-positivista de normalidade. Por isso, é necessário definir novas formas de tratar questões do diferente na escola e em todos os ambientes sociais.

Nesse contexto, a constituição de uma educação inclusiva já se tornou uma exigência nas escolas do Brasil, seja por uma ordem legal, por conta das políticas públicas, ou mesmo por uma pressão cada vez mais organizada de grupos sociais ligados à questão das pessoas com 
deficiência (ALVES et al., 2013). Nessa perspectiva, a educação inclusiva, configura-se, portanto, como uma reforma educacional que abarca um âmbito muito alargado e capaz de promover uma mudança de orientação com seu novo sentido da inclusão. Sendo assim, não se restringe apenas à mudança curricular e garantia da acessibilidade desses alunos à escola regular. Trata-se de uma reforma bem mais densa que conglomera os valores e as práticas de todo o sistema educativo tal como ele é comumente concebido (ALVES et al., 2014).

A luta hoje é para que este direito seja respeitado e que as escolas se tornem um espaço inclusivo de todos e para todos. A escola para todos deve atender qualquer tipo de aluno de forma eficaz, respeitando a especificidade de cada um, para não diferenciar ou estigmatizar, mas, para incluir de maneira adequada todos os alunos. Este novo modelo de escola implica a busca de novas metodologias, alternativas e procedimentos que garantam o acesso e a permanência de todos os educandos na rede regular de ensino. Assim, o que se deseja na realidade é uma escola inclusiva, compromissada com a construção de uma sociedade mais justa e igualitária.

Destarte corrobora-se com Zuccheti (2011) quando diz que o professor de Educação Física representa condição sine qua non para que a inclusão se torne efetiva, por ser instrumentalizado de conhecimentos e técnicas que contribuem para melhoria da formação e da saúde dos alunos, além do acesso destes à diversidade.

O professor de Educação Física, através de sua prática pedagógica comprometida com o desenvolvimento social, contribui sobremaneira no campo da educação inclusiva, fazendo uso de novas propostas e abordagens teórico-metodológicas, apresentando o novo e o desconhecido aos alunos, pois a partir da instigação e do desafio, os alunos seguem assimilando melhor a informação transformando-a em conhecimento, estruturando suas funções motoras e mentais (CRUZ, 2011). Ainda, a partir da práxis eficiente, é estimulada a criatividade, a expressão corporal, a liberdade de movimentos, a ludicidade, enfim, são implementadas atividades capazes de proporcionar aos alunos experiências que favorecem a cooperação, a sociabilidade, bem como o seu desenvolvimento psicomotor (ZUCCHETI, 2011).

Nesse panorama, surge a necessidade de analisar o pensamento dos professores de Educação Física que atuam na rede regular de ensino, visto que são atores sociais envolvidos no processo de inclusão/exclusão dos alunos com deficiência. Em contrapartida, é necessária uma discussão profunda sobre o papel social do docente nesse processo de mudança, o que implica dizer que a questão da formação do professor deva ser uma das questões centrais na política de 
educação inclusiva, devendo ser de forma contínua, e de acordo com Alves e Duarte (2013) é o novo desafio a ser enfrentado pelos professores na busca pela superação de uma concepção de educação excludente e classificatória por uma concepção de educação inclusiva.

A partir das premissas descritas anteriormente, este estudo objetivou analisar as percepções de professores de Educação Física sobre a inclusão de alunos com deficiência no sistema regular de ensino.

\section{Método}

Trata-se de uma pesquisa descritiva e analítica, de abordagem qualitativa. A escolha da realização deste tipo de estudo se deu por entender que o mesmo responde às questões particulares, num espaço mais profundo das relações, considerando como sujeitos do estudo pessoas pertencentes a determinada condição social, com suas crenças, valores e significados (MINAYO; DESLANDES; GOMES, 2012).

Esta pesquisa foi realizada nas três maiores escolas públicas estaduais do município de Jequié, Bahia. A escolha por estas instituições de ensino vem justamente pela localização centralizada das mesmas e por elas abrigarem alunos vindos de diversos bairros e localidades do município e da região, e também por entender que elas abrigam o maior número de alunos da rede regular de ensino.

O critério de escolha para selecionar os sujeitos da pesquisa deve-se ao fato de que os professores de Educação Física em questão atuam em grandes instituições públicas e estaduais de ensino da rede regular e possuem vínculo efetivo com o Estado. Assim, considerando o caráter e o objetivo desta pesquisa, foram informantes do estudo todos os professores de Educação Física das três escolas selecionadas, totalizando nove professores, três de cada escola, sendo que todos os docentes têm como formação a graduação em licenciatura em Educação Física.

Foi utilizada como técnica de coleta de dados a entrevista semiestruturada, cujo roteiro foi organizado com quatro eixos norteadores. Os dados da pesquisa foram produzidos no período de março a setembro de 2013. Os resultados foram tratados, organizados e analisados de acordo com a Técnica de Análise de Conteúdo, segundo Bardin (2011), e obedecendo aos passos: $1^{\mathrm{a}}$ FASE: pré-análise, $2^{\text {a }}$ FASE: exploração do material e $3^{\mathrm{a}}$ FASE: tratamento dos dados, inferência e 
interpretação. Após transcrição das entrevistas, os dados foram apresentados em categorias que emergiram a partir da produção dos dados.

Inicialmente realizamos a leitura flutuante dos depoimentos definindo o corpus do trabalho constituído de 9 entrevistas. Em seguida, procedeu-se a leitura exaustiva dos depoimentos, para estabelecer os objetivos da análise. Foram selecionados elementos como palavras e frases dotadas de significados, sendo considerados como variáveis importantes ao processo de avaliação do sentido das opiniões (BARDIN, 2011). Ao final de cada recorte realizado nas falas dos sujeitos será indicado entre parênteses uma identificação alfanumérica (P1-P9).

Dessa forma, buscando atender à Resolução 466/2012 (BRASIL, 2012), que aborda a pesquisa com seres humanos, respaldada nos aspectos éticos e legais esse estudo respeitou todos os preceitos da ética em pesquisa. Por sua vez, vale ressaltar que os informantes deste estudo preencheram o Termo de Consentimento Livre e Esclarecido, onde foi assegurado sigilo e anonimato, e os mesmos cederam os direitos de uso e divulgação de sua transcrição literal, bem como autorização para publicação dos resultados da pesquisa em revista científica.

\section{Resultados e Discussão}

Este estudo traz dados que apontam os olhares dos professores de Educação Física acerca desse processo de educação inclusiva, alertando também para as suas dificuldades. Além disso, as reflexões desta pesquisa assumem papel relevante no fazer educacional, cujo um dos maiores desafios da atualidade é de promover a educação para todos os alunos, tendo como referência a diversidade humana, que não deve ser vista como obstáculo para a ação educativa, mas como fator de enriquecimento cultural e social para o aprendizado da comunidade escolar.

Como resultados da pesquisa encontramos quatro categorias, sendo intituladas: percepção sobre educação inclusiva; a escola como espaço inclusivo; formação profissional frente ao processo de inclusão; e, prática pedagógica no contexto inclusivo, que serão descritas, analisadas e discutidas a seguir.

\section{- Percepção sobre educação inclusiva}

A percepção sobre Educação Inclusiva neste estudo refere-se às percepções dos 
professores entrevistados no que concerne ao ensino de alunos com deficiência, numa perspectiva de desenvolver um trabalho interativo em prol da dignidade humana, valorizando cada educando através do respeito pela diversidade.

Conforme o relato dos pesquisados pode-se observar a sustentação para a categoria percepção inclusiva, onde são apresentadas as unidades de análise temática sobre a percepção dos sujeitos sobre a inclusão das pessoas com deficiência no sistema regular de ensino.

Para mim inclusão é colocar o aluno com necessidade especial na classe regular (P1).

Fazer atividades que integrem todos os alunos na mesma classe (P3).

É propiciar a todos os indivíduos uma educação legal e um ensino de qualidade para que ele possa crescer dentro e fora do ambiente escolar (P6).

É possível fazer inclusão a partir de uma visão diferenciada de mundo, com compromisso social e pensando na transformação e emancipação humana $(\mathrm{P7})$.

Ao avaliar as unidades de análise dispostas acima, observa-se que a maioria dos entrevistados ainda possui uma visão limitada do que vem a ser a educação inclusiva, pois, ao contrário do que pensam, não se trata apenas de pôr esse aluno na classe regular, o objetivo/conceito vai muito além disso.

Inclusão é conviver com o outro respeitando as suas diferenças individuais, sociais, culturais, étnicas, físicas e religiosas. As diferenças precisam ser consideradas não como sinônimo de incapacidade, mas como características próprias do indivíduo, pois cada um tem seu ritmo de aprender, que deve ser respeitado e estimulado. É essencial analisar a inclusão também pela perspectiva da exclusão para identificar os fatores responsáveis por tal situação e acentuar o trabalho com vistas a sua minimização, "permitindo que o aluno com deficiência se sinta incluído. No entanto, é fundamental que este conhecimento seja estruturado a partir da percepção subjetiva do aluno com deficiência” (ALVES; DUARTE, 2013, p. 131).

Esse sentimento de incluir pessoas que vivem diferentemente o acesso ao conhecimento deveria contagiar a coletividade, ao passo que essa convivência dá margem à idealização de novas experiências curriculares, possibilitando uma flexibilização da grade de disciplinas e reestruturação de séries. Imbuída nessa perspectiva, a educação inclusiva transformar-se-ia num atendimento educacional especializado, respeitando a idiossincrasia de cada aluno e funcionando como suporte às atividades desenvolvidas em sala de aula e nas relações gerais da escola (ANJOS; ANDRADE; PEREIRA, 2009). 
De outro modo, existe um professor que não concorda como a inclusão está ocorrendo nos dias atuais, afirmando que:

É uma atitude inescrupulosa do Estado de considerar todos como "iguais", pois acho que é algo que o sistema educacional regular de ensino não está pronto para abraçar (P9).

Diante dessa realidade, faz-se necessária a (re)construção da matriz escolar para que a mesma atue como força propulsora no atendimento às necessidades concretas das pessoas que dela fazem parte. É a escola que deve adaptar-se ao aluno e não o inverso. Mantoan (1997) argumenta que inclusão é convidar aqueles que de alguma forma tem esperado para entrar e pedir-lhes para ajudar a desenhar novos sistemas que encorajem todas as pessoas a participar da completude de suas capacidades. Assim, como companheiros e como membros, inclusão significa todos juntos dando apoio e sendo suporte uns dos outros.

\section{- A escola como espaço inclusivo}

No contexto atual do cenário nacional é possível notarmos os grandes discursos, onde é evidenciada a afirmação de que todos os alunos, independente de suas necessidades específicas, devem estar inseridas no âmbito educacional e social da escola sem que antes tenham sido excluídas pelo próprio aparelho educacional, sendo necessário que elas tenham direito a igualdade de ingresso, acesso e permanência na instituição escolar. Para que ocorra a permanência e aprendizagem dos educandos na escola alguns fatores devem ser levadas em consideração: aceitação das diferenças, motivação e autoconfiança dos alunos percebida quando os mesmos adentram o ambiente escolar.

Essas reflexões e ações políticas, sociais e culturais que impulsionam e avançam a favor da inclusão educacional estão delineada através dos diversos documentos (Constituição da República Federativa do Brasil (1988), Declaração Mundial sobre a Educação para Todos (UNESCO, 1990), Declaração de Salamanca- Sobre Princípios, Políticas e Práticas na Área das Necessidades Educativas Especiais (UNESCO, 1994), Política Nacional de Educação Especial (BRASIL, 1994), Lei de Diretrizes e Bases da Educação Nacional (BRASIL, 1996), Estatuto da Criança e do Adolescente (BRASIL, 2006), Política Nacional de Educação Especial na perspectiva da Educação Inclusiva (BRASIL, 2008), entre outros) que garantem a inclusão dos que de certa forma estão de fora (MAHL, 2012, p. 33). 
A respeito da política de inclusão educacional, a nova Lei de Diretrizes e Bases da Educação Nacional, LDB n. ${ }^{\circ}$ 9394/96, recomenda a inclusão de alunos com deficiência em sala de aula regular, desenvolvendo suas atividades em conjunto com os demais (BRASIL, 1996). Nesse sentido, foi solicitado aos professores entrevistados informações a cerca de suas percepções sobre esse novo paradigma de inclusão de alunos com deficiência em classes regulares, as quais estão dispostas abaixo:

A escola deve ser um espaço inclusivo, embora exista grandes dificuldades como falta de apoio pedagógico, financeiro e falta de cursos específicos de formação complementar (P1, P2).

Não concordo com a política como está estabelecida, antes de acontecer a inclusão deve haver uma reestruturação dos espaços físicos e um aperfeiçoamento profissional para que todos estejam preparados para trabalhar com esse tipo de público, não é possível desenvolver a inclusão dessa forma (P3, P4, P8).

A partir do que foi explicitado pelos professores, é possível inferir que embora seja a educação inclusiva um direito de todos, o sistema educacional, por si só, não oferece condições para o atendimento do aluno com deficiência. Fica evidente nas falas o pensamento interno do ser professor no contexto da educação inclusiva, que condiz com a percepção de que a inclusão ocorre como algo imposto, sem margem para escolhas, opções ou discussões sobre essa nova realidade.

Nesse mesmo sentido, Alves et al. (2013) afirmam que o que se intui é que as discussões em torno desta temática e ações só se fazem presentes no espaço escolar a partir do momento em que o professor se depara com a presença do aluno com deficiência em sala de aula, do contrário, esta temática torna-se assunto distante da escola.

Contudo, a escola deve ter a capacidade de reavaliar sua estrutura física, arquitetônica e estrutural, de forma que atenda às necessidades e peculiaridades de cada um de seus alunos, traçando numa única sinergia estratégias e novas formas que favoreçam a formação integral, fazendo uma verdadeira alusão à inclusão. É fato, fatores como tempo, responsabilidade e comprometimento de todos os sujeitos envolvidos no processo são importantes para a construção de uma escola verdadeiramente inclusiva (ROCKWELL; EZPELETA, 2007).

Fica evidente nas justificativas dos depoentes que os professores em questão não são contrários à inclusão escolar. Diferentemente, eles ainda não se sentem sujeitos ativos desse decurso, onde entendemos que muitas outras questões que perpassam pelo processo de inclusão estão pendentes. Apenas a execução de leis que tratem da inclusão não garantem a eficácia e 
efetividade desse projeto, o que se caracteriza como apenas um impulsionador na construção subjetiva sobre esse novo panorama da inclusão (DUEK; NAUJORKS, 2007).

Nesse ínterim, Sales, Missias-Moreira e Miranda (2014, p. 328):

O processo de inclusão é complexo e caro e exige uma redefinição do olhar da sociedade no que tange à pessoa com deficiência, de políticas públicas de caráter inclusivo, mas essas dependem fundamentalmente de um posicionamento ético, político e social.

Portanto, mesmo que as políticas públicas de inclusão se difundam discursivamente e mesmo com o apoio em pedagogias culturais, é necessário que toda a população seja ensinada e convencida sobre a inclusão, pois será realizada integralmente quando todos os corpos estiverem juntos no mesmo espaço.

\section{- Formação profissional frente o processo de inclusão}

É evidente que o aspecto da formação profissional deva ser um dos destaques nas pesquisas científicas, debates profissionais, acadêmicos e políticos referentes à inclusão de alunos com deficiência no âmbito escolar. Existe, portanto, a necessidade de uma formação adequada para que as demandas e necessidades possam ser supridas, não se esgotando as possibilidades de aprendizagem e aperfeiçoamento dos professores na formação inicial construída na graduação.

A partir dos relatos dos professores, podemos observar as ideias que sustentam a categoria formação profissional frente o processo de inclusão, onde são apresentadas a percepção dos sujeitos sobre a formação de professores para atuar no contexto inclusivo.

Não estou satisfeito com a formação em relação aos princípios da inclusão, ela não nos prepara para atender ao novo paradigma da educação inclusiva, é preciso incluir no currículo universitário disciplinas que atendam a essa perspectiva (P1, $\mathrm{P} 2, \mathrm{P} 9)$.

Minha formação inicial em Educação Física não me deu subsídios para atuar com a complexidade da educação inclusiva (P3, P7).

A educação na perspectiva da inclusão é dinâmica, complexa, necessária e indispensável, no entanto, mudam-se os modelos de educação, mas a formação continua a mesma. Não atendendo dessa forma as questões ligadas a educação inclusiva (P5).

A partir das falas, que indicaram unanimidade na percepção sobre a formação profissional, é evidenciada uma urgente necessidade de formação contínua em serviço, para que a educação inclusiva seja efetivada com qualidade. É perceptível que a formação de professores é um dos aspectos relevantes para que a proposta inclusiva seja de fato implementada (PLETSCH, 
2009). A formação dos docentes frente às questões da inclusão no contexto escolar torna-se um fator decisivo para o sucesso e a materialização das leis no dia a dia das escolas, buscando a solidificação de uma educação verdadeiramente inclusiva, assegurando o respeito à diversidade e peculiaridade dos discentes (TERRA; GOMES, 2013).

Concordamos com Saviani (2009), quando argumenta que é fato que as políticas públicas de inclusão no Brasil avançaram, mas no que tange a formação do professor, esta encontra-se fragmentada e não deve ser dissociada dos entraves e problemas que envolvem as condições de trabalho dos docentes. As péssimas condições de trabalho dos professores, além de neutralizarem as ações docentes, dificultam as condições da boa formação, pois funcionam como grande fator de desmotivação a procura por cursos de formação de professores.

No que concerne à formação de professores, é necessário que haja um trato minucioso no conhecimento teórico que seja capaz de alargar a compreensão dos problemas existentes e que são diretamente enfrentados pelos docentes, se tornando condição necessária de superação dos desafios e entraves existentes nessa área (SANTOS, 2004), sendo entendida como um continuum (LIMA, 2009). Nesse mesmo sentido, tanto a formação básica, quanto a continuada devem responder as novas demandas, traçando um perfil de docente que se configura por sua função em eleger e sublimar a diversidade de alternativas pedagógicas aquela que lhe aparente ser a mais indicada à realidade da aula e da escola numa perspectiva inter/multicultural. No entanto, de acordo a professora Guacira Lopes Louro (2011) a noção de multiculturalismo tanto pode servir para amenizar divergências e acomodar histórias de subordinação, quanto pode servir como alavanca para a luta política e para a compreensão da formação histórica das diferenças.

Nesse ínterim, podemos perceber que a formação do professor é um fator muito importante para favorecer a educação inclusiva. O Ministério da Educação e Desporto, no ano de 1994, percebeu a necessidade de acrescentar nos currículos de formação de professores e de outras categorias profissionais que trabalhassem com pessoas com deficiência, assuntos ligados a inclusão. Na lei n ${ }^{\circ} 1.793$ de dezembro de 1994 está preconizada que os cursos de graduação em Educação Física deveriam ter sua grade curricular conteúdos relacionados aos aspectos educacionais, éticos e políticos de integração de pessoas com deficiência (BRASIL, 1994).

Nesse sentido, a partir dos dados levantados neste estudo, podemos depreender que os currículos de formação de professores e os programas de capacitação devem estar voltados à 
instrumentalizar o professor para atender, de forma competente e coerente, os alunos com deficiência nas turmas regulares de ensino.

\section{- Prática pedagógica no contexto inclusivo}

O problema na educação inclusiva não é apenas no sentido pedagógico, mas também de ordem estrutural, arquitetônica, funcional e atitudinal, portanto é necessário que as pessoas envolvidas nesse processo tomem consciência do que vem significar a inclusão social e qual papel que cada um deve ter para uma efetiva implantação da mesma.

Por mais que os discursos tenham avançado nitidamente, a realidade educacional ainda está pautada numa escola tradicional, que não dialoga com o que está ocorrendo ao seu redor, onde o máxime objetivo da educação tem sido restrito no sentido de se ter uma profissão, possibilitando-lhe futuros lucros.

A partir das falas dos professores entrevistados, podemos observar pensamentos que trazem informações capazes de sustentar essa categoria intitulada prática pedagógica no contexto inclusivo, sendo apresentadas abaixo as percepções dos educadores envolvidos no estudo sobre a atuação/intervenção dos mesmos no contexto inclusivo:

Considero urgente a revisão dos currículos dos cursos de formação de professores para que minha prática pedagógica possa ser eficiente e venha a atender aos objetivos estabelecidos pela política nacional de educação inclusiva $(\mathrm{P} 2)$.

A maior dificuldade para trabalhar com esse público ainda é por causa da formação, seguida da deficiência na estrutura física e nos recursos materiais, além da falta de apoio da gestão escolar, portanto deve haver uma reformulação em todos os aspectos da escola para que possa ocorrer de fato a inclusão escolar (P6).

Preciso entender melhor o que significa inclusão no contexto da escola, para que possa me atentar e ter uma prática pedagógica coerente, mas preciso do apoio da direção e do setor pedagógico da escola, principalmente no sentido de capacitações porque o problema da educação inclusiva é concebida na formação inicial que é fragmentada e não me preparou para essa realidade (P8).

O que podemos perceber é que mesmo o professor que entende seu papel social como relevante nessa perspectiva da política da inclusão, o mesmo tem dificuldades em exercer sua função pela deficiência que existe em sua qualificação, não havendo uma constante preocupação em analisar, discutir e estudar as possibilidades de intervenções pedagógicas no paradigma da inclusão. Desta maneira, constatamos que, embora com limitações, os mesmos são 
comprometidos com a prática docente, e esse resultado também foi encontrado em estudo realizado por Rodrigues e Darido (2008) e por Duarte et al. (2015).

Sendo possível evidenciar que os educadores demonstraram significativa preocupação e apreensão não pela deficiência em si, mas no tocante ao próprio aluno, no sentido de não saberem exatamente como articular atividades que permitissem o educando a participar de maneira dinâmica do processo educativo.

Ainda, contribuem com o presente estudo Mattos (2012) e Alves e Duarte (2013), ao argumentarem que, para favorecer de fato a inclusão, é necessária uma prática pedagógica coerente com as necessidades e demandas da realidade escolar, sendo preciso ponderar as individualidades, singularidades e peculiaridades de cada um, além da fusão de culturas que se fazem presentes, direcionando o olhar para uma parte no todo e o todo na parte.

Nesse contexto, sob o olhar de Andrade e Freitas (2016, p. 1173):

Infere-se que ações pedagógicas que visem à elaboração de conhecimentos escolares por
alunos com deficiência são possíveis de ocorrer quando tais alunos são compreendidos
pela via das possibilidades socioculturais, e não, somente, pelo olhar biológico, que
naturaliza e limita tanto as ações dos professores para ensinarem, como as oportunidades
para os alunos aprenderem.

No que concerne à epistemologia da práxis pedagógica dos professores de Educação Física frente o processo de inclusão é salutar que seja percebida a relevância da interação e relação entre professor e aluno como fonte de origem do desenvolvimento humano e dos processos de aprendizagem (DUARTE et al., 2015). De acordo com essa realidade, Vygotski (2000) corrobora salientando que "nós nos tornamos nós mesmos a partir dos outros", podendo ser a afetividade um dos caminhos para que a inclusão aconteça, tornando-se propulsora da aprendizagem e mediadora das relações/relacionamentos desenvolvidos, buscando a inserção e inclusão não apenas dos alunos com deficiência, mas de todos os educandos.

Embora esteja evidente nas falas dos professores, durante todo o estudo, que grande parte das ações pedagógicas contemplaram a inclusão dos alunos com deficiência na rede regular, os relatos dos entrevistados também indicam que existe uma debilidade na construção teórica para embasamento e fundamentação consistentes que sejam capazes de subsidiar suas intervenções, ações e práticas pedagógicas.

A Educação Física como componente curricular deve pautar a sua ação pedagógica pelos fundamentos da inclusão, considerando as necessidades e os interesses de todos os seus alunos e 
oferecendo a eles subsídios possíveis para que possam experimentar diferentes formas de movimentos corporais, sejam por meio das atividades físicas, esportivas ou recreativas, a fim de contribuir para seu desenvolvimento global (FREITAS; SALES; MISSIAS-MOREIRA, 2016).

Ainda, é importante e essencial que, para que essa prática atenda às demandas, anseios e necessidades dos alunos, os professores recebam o apoio da equipe gestora e suporte pedagógico necessário para desenvolver eficazmente o seu trabalho, atingindo dessa forma os objetivos de uma educação verdadeiramente inclusiva.

Nessa lógica, o educador deve avaliar suas ações pedagógicas (DUARTE et al., 2015) para transformar sua intervenção docente em algo ativo e dinâmico, em que seus alunos consigam ultrapassar os desafios e obstáculos sejam eles de ordem social, cognitiva, afetiva, física, dentre outros. Nesse momento o professor deve abarcar e fazer uso de toda a gama de conhecimentos e experiências adquiridas na vida e na prática laboral para promover e proporcionar o crescimento dos educandos, transformando, dessa forma, sua prática teórica em uma práxis social efetiva.

\section{Considerações finais}

É possível afirmar, após a realização desta pesquisa, a importância de se discutir a educação no Brasil sobre o prisma da inclusão, visto que a população brasileira tem como enorme desafio a construção de uma sociedade mais justa e igualitária, na qual o princípio de igualdade, tão conclamado nas leis do país, seja garantido, também, a todos sem exceção, pelo acesso e permanência de iguais condições e oportunidades educacionais para que todos possam desenvolver suas potencialidades e participar ativamente da sociedade.

Como resultado principal deste trabalho, constata-se que para efetivar verdadeiramente a inclusão desses alunos na escola regular, na percepção dos professores, dentre outros fatores, fazse necessária e urgente a formação adequada dos docentes para aprimorarem seu fazer pedagógico, visando ao atendimento às necessidades individuais de seus alunos; aquisição de materiais e recursos para o trabalho específico; apoio de outros profissionais da área (psicólogos, terapeutas, pedagogos, etc.); eliminação das barreiras arquitetônicas na maioria das escolas; melhoria das condições de trabalho, etc.

Existem, portanto, alguns desafios a serem vencidos para que o processo de inclusão dos alunos com necessidades especiais aconteça: a educação deve ser voltada para todos os 
indivíduos envolvidos no processo educacional; respeitar as diferenças individuais atentando a diversidade humana; adaptar o processo de ensino-aprendizagem às necessidades do aluno; sensibilizar e conscientizar os professores, pais, alunos e comunidade para um papel mais ativo em prol da escola inclusiva.

Sendo assim, é de vital importância que as diretrizes norteadoras da educação nacional contemplem todos os alunos e que a escola necessita ser de qualidade, pautada nos princípios de respeito às individualidades, livre de qualquer forma de preconceito, compreendendo a aprendizagem como processo de construção contínuo de cada indivíduo na interação com o outro.

Para isto, faz-se necessário que os cursos de licenciatura plena em Educação Física forneçam a devida instrumentalização aos professores que fizerem parte de seus programas de estudo, como também são importantes: os sistemas de apoio aos alunos, professores e família; cobrar as autoridades legais que as leis de amparo as pessoas com deficiência sejam cumpridas.

Concluindo, podemos afirmar que a singularidade é a característica principal do ser humano, não existindo pessoas iguais. A diversidade é uma realidade em nossa sociedade, e o respeito a diversidade é fundamental. É preciso acreditar, confiar e criar oportunidades para o desenvolvimento do potencial de cada um, no seu limite e em suas capacidades reais. Assim, a convivência é um dos princípios básicos no processo da inclusão e na reciprocidade entre todas as crianças.

\section{Referências}

ALVES, Maria Luísa Tanure; DUARTE, Edison. A exclusão nas aulas de educação física: fatores associados com participação de alunos com deficiência. Movimento, Porto Alegre, v. 19, n. 1, p. 117-137, jan. 2013.

ALVES, Tássia Pereira et al. Inclusão de alunos com surdez na educação física escolar. Revista Eletrônica de Educação, São Carlos, v. 7, n. 3, p. 192-204, set. 2013.

ALVES, Tássia Pereira et al. Representações de alunos surdos sobre a inclusão nas aulas de educação física. Revista Educação Especial, Santa Maria, v. 27, n. 48, p. 65-78, jan. 2014.

ANDRADE, J. M. A.; FREITAS, A. P. Possibilidades de atuação do professor de educação física no processo de aprendizagem de alunos com deficiência. Movimento, Porto Alegre, v. 22, n. 4, p. 1163 1173, out. 2016.

ANJOS, Hildete Pereira dos; ANDRADE, Emmanuele Pereira de; PEREIRA, Mirian Rosa. A inclusão escolar do ponto de vista dos professores: o processo de constituição de um discurso. Revista Brasileira de Educação, Rio de Janeiro, v. 14, n. 40, p. 116-129, abr. 2009.

BARDIN, Laurence. Análise de conteúdo. Lisboa: Edições 70, 2011. 
BRASIL. Conselho Nacional de Saúde (CNS). Resolução n. 466, de 10 de dezembro de 2012. Diretrizes e Normas regulamentadoras de pesquisa envolvendo seres humanos. Brasília: CNS, 2012.

BRASIL. Lei de Diretrizes e Bases da Educação Nacional. Lei n. 9394/96 de 20 de dezembro de 1996. Brasília, 1996.

BRASIL. Ministério da Educação. Secretaria de Educação Especial. Diretrizes Nacionais para a Educação Especial na Educação Básica. Brasília: MEC/SEESP, 2001.

BRASIL. Ministério da Educação. Secretaria de Educação Especial. Política Nacional de Educação Especial na Perspectiva da Educação Inclusiva. Brasília: MEC, 2008.

BRASIL. Ministério da Educação e Desporto. Lei no 1.793 de dezembro de 1994. Brasília: MED, 1994. CRUZ, Marlon Messias Santana. Educação física inclusiva na escola: em busca de uma escola plural. Revista da FACED, Salvador, v. 20, n. 1, p. 127-133, jul. 2011.

DUARTE, Anne Caroline et al. Professores de educação física e a sua prática pedagógica em classes que alunos com deficiência estão inseridos. Pensar a Prática, Goiânia, v. 18, n. 1, p. 27-39, jan. 2015.

DUEK, Viviane Preichardt; NAUJORKS, Maria Inês. Docência e inclusão: reflexões sobre a experiência de ser professor no contexto da escola inclusiva. Revista da FAEEBA - Educação e

Contemporaneidade, Salvador, v. 16, n. 27, p. 41-53, jan./jun. 2007.

FREITAS, Michele Gomes; SALES, Zenilda Nogueira; MISSIAS-MOREIRA, Ramon. Inclusão de alunos com deficiência visual nas aulas de educação física escolar. Revista Eletrônica de Educação, São Carlos, v. 10, n. 1, p. 100-109, março 2016.

LIMA, Emilia Freitas. A formação inicial de professores e a didática na perspectiva inter/multicultural. Educação (UFSM), Santa Maria, v. 34, n. 1, p. 165-178, jan. 2009.

LOURO, Guacira Lopes. Educação e docência: diversidade, gênero e sexualidade. Formação Docente, Belo Horizonte, v. 3, n. 4, p. 62-70, jan. 2011.

MAHL, Eliane. Práticas pedagógicas dos professores de educação física frente a inclusão de alunos com deficiência. 2012. 156p. Dissertação (Mestrado em Educação Especial) - Universidade Federal de São Carlos, São Carlos, 2012.

MANTOAN, Maria Tereza Eglér. A integração de pessoas com deficiência: contribuições para uma reflexão sobre o tema. São Paulo: SENAC, 1997.

MATTOS, Sandra Maria Nascimento de. Inclusão/exclusão escolar e afetividade: repensando o fracasso escolar. Educar em Revista, Curitiba, n. 44, p. 217-233, abr./jun. 2012.

MINAYO, Maria Cecília de Souza; DESLANDES, Suely Ferreira; GOMES, Romeu. Pesquisa social: teoria, método e criatividade. Rio de Janeiro: Vozes, 2012.

OLIVEIRA, Maria Auxiliadora Monteiro; SOUZA, Sandra Freitas de. Policies for inclusion: study in a State School in Belo Horizonte. Educar em Revista, Curitiba, n. 42, p. 245-261, out. 2011.

PLETSCH, Márcia Denise. A formação de professores para a educação inclusiva: legislação, diretrizes políticas e resultados de pesquisas. Educar em Revista, Curitiba, n. 33, p. 143-156, 2009.

ROCKWELL, Elsie; EZPELETA, Justa. A escola: relato de um processo inacabado de construção. Currículo sem Fronteiras, v. 7, n. 2, p. 131-147, jul. 2007.

RODRIGUES, Heitor de Andrade; DARIDO, Suraya Cristina. As três dimensões dos conteúdos na prática pedagógica de uma professora de educação física com mestrado: um estudo de caso. Revista de

Educação Física/UEM, Maringá, v. 19, n. 1, p. 51-69, jan. 2008.

Quaestio, Sorocaba, SP, v. 19, n. 2, p. 291-306, ago. 2017. 
SALES, Zenilda Nogueira; MISSIAS-MOREIRA, Ramon; MIRANDA, Theresinha Guimarães. Percepções sobre a inclusão de alunos com necessidades educacionais especiais no ensino superior. Quaestio: revista de estudos em educação, Sorocaba, v. 16, n. 2, p. 315-330, nov. 2014.

SANTOS, Lucíola Licínio. Formação de professores na cultura do desempenho. Educação \& Sociedade, Campinas, v. 25, n. 89, p. 33-42, set. 2004.

SAVIANI, Demerval. Formação de professores: aspectos históricos e teóricos do problema no contexto brasileiro. Revista Brasileira de Educação, Rio de Janeiro, v. 14, n. 40, p. 143-155, 2009.

TERRA, Ricardo Nogueira; GOMES, Claudia Gomes. Inclusão escolar: carências e desafios na formação e atuação profissional. Revista Educação Especial, v. 26, n. 45, p. 109-124, jan./abr. 2013.

VIGOTSKI, Lev Semenovitch. Manuscrito de 1929. Educação \& Sociedade, Campinas, v. 21, n. 71, p. 21-44, jul. 2000.

ZUCCHETI, Dinora Tereza. A inclusão escolar vista sob a ótica de professores da escola básica.

Educação em Revista, Belo Horizonte, v. 27, n. 2, p. 197-218, ago. 2011.

Ramon Missias-Moreira - Universidade Federal da Bahia. Salvador | BA | Brasil. Contato: ramonefisica@ hotmail.com

Artigo recebido em: 26 nov. 2016 e aprovado em: 16 jun. 2017.

Quaestio, Sorocaba, SP, v. 19, n. 2, p. 291-306, ago. 2017. 